\title{
Preliminary analysis of thermal anomalies before the 2010 Baja California M7.2 earthquake
}

\author{
Y. JIE and G. GUANGMENG \\ Remote Sensing Center, Nanyang Normal University, China \\ Corresponding author: G. Guangmeng; email: guogm@igsnrr.ac.cn
}

Received May 4, 2012; accepted May 9, 2013

\begin{abstract}
RESUMEN
Este trabajo presenta un análisis preliminar de las anomalía térmicas observadas antes del terremoto de magnitud 7.2 ocurrido el 4 de abril de 2010 en Baja California. Los resultados muestran que la temperatura superficial del aire en la estación de Mexicali (la más cercana al epicentro) alcanza un valor máximo el 30 de marzo (que también es el máximo registrado entre el 1 de enero y el 4 de abril de 2010). Las estaciones meteorológicas lejanas al epicentro (distantes $100 \mathrm{~km}$ de éste) no muestran otra anomalía. En particular, los datos de temperatura del aire del Análisis Final de los Centros Nacionales de Predicción Ambiental (NCEP-FNA, por sus siglas en inglés) muestran un cambio máximo de temperatura entre el 30 y 31 de marzo en el punto de malla del epicentro, en tanto que los otros 7199 puntos de malla muestran cambios medianos a bajos. La temperatura de la brillantez medida por el radiómetro avanzado de barrido por microondas, acoplado al sistema de observación de la Tierra del satélite Aqua (AMSR-E, por sus siglas en inglés) también muestra un incremento el 31 de marzo. Los resultados del análisis térmico multiparamétrico cumplen de manera adecuada con los criterios DTS (desviación [D], sincronía temporal [T] y consistencia espacial [S]), de manera que pueden considerarse como anomalías térmicas sísmicas. Este análisis podría contribuir al pronóstico confiable de terremotos.
\end{abstract}

\begin{abstract}
This paper presents a preliminary analysis of thermal anomalies before the Baja California M7.2 earthquake occurred on April 4, 2010. The results show that surface air temperature of the Mexicali station, which is the closest one to the epicenter, reaches its maximum value on March 30, which is also the maximum value from January 1 to April 10, 2010. Weather stations far away from the epicenter (100 km away) show no other thermal anomaly. In particular, the National Centers for Environmental Prediction Final Operational Global Analysis (NCEP-FNL) air temperature data show a maximum temperature change between March 30 and 31 at the epicenter grid point, while the other surrounding 7199 grid points show medium to low temperature change. The microwave brightness temperature measured by the Advanced Microwave Scanning Radiometer on board the EOS Aqua satellite (AMSR-E) also shows an increase on March 31. The results of multiple thermal parameters analysis obey well the DTS criterions: deviation (D), time synchronism (T), and space consistency (S), so they can be considered as convincing seismic thermal anomalies. This analysis might contribute to make reliable earthquake predictions.
\end{abstract}

Keywords: Earthquake anomaly recognition, air temperature, NCEP-FNL, AMSR-E.

\section{Introduction}

On January 12, 2010 a M7.0 earthquake occurred in Haiti and caused a big number of casualties. Three months later a M7.2 earthquake occurred on April 4, 2010 at Baja California, Mexico. Its epicenter was located at $32.259^{\circ} \mathrm{N}, 115.287^{\circ} \mathrm{W}$ with $10 \mathrm{~km}$ depth
(Fig. 1). These two strong earthquakes are both rare in recent years in the American continent. The Haiti earthquake has been widely studied by authors such as Pulinets (2010), who found that total electron content (TEC) increased over the epicenter a few days prior to the earthquake, and Akhoondzadeh and 


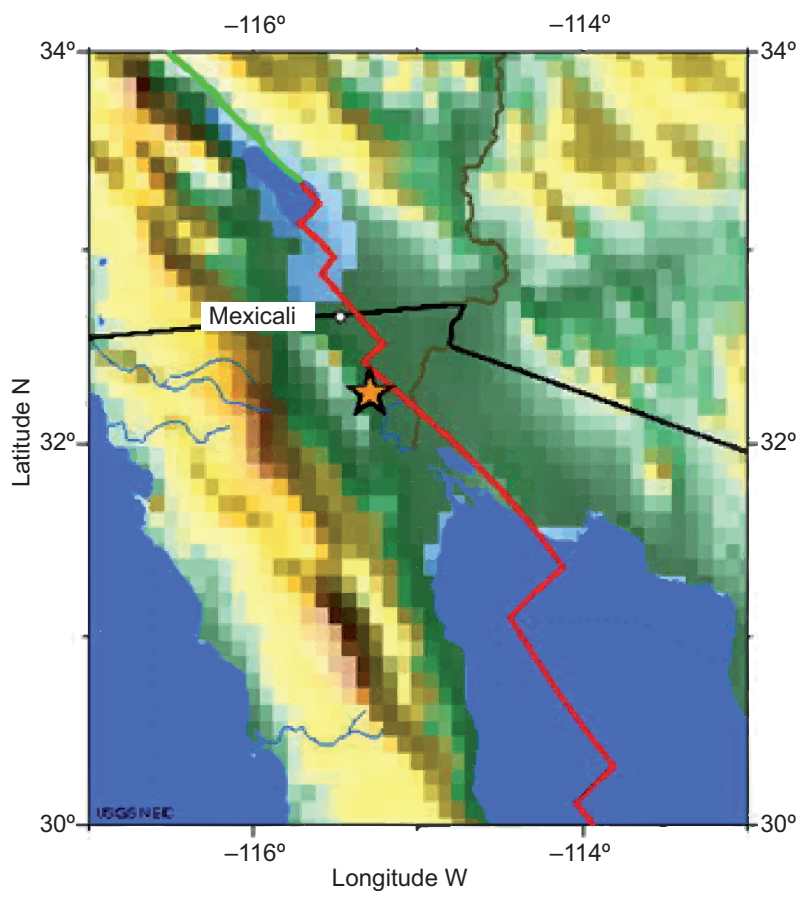

Fig. 1. M7.2 Baja California earthquake epicenter (star) together with the fault line (in red) and national boundaries (in black).

Saradjian (2011), who used the interquartile method, wavelet transformation and Kalman filter method to identify TEC anomalies before the quake. But strangely, there is little research published until now about the Baja California M7.2 earthquake.

Dunajecka and Pulinets (2005) used surface air temperature data and studied the thermal anomalies before some strong earthquakes in Mexico. They found that these anomalies are expressed in the form of sharp changes of ground air temperature and relative humidity around one week before the seismic shock. In the case of the M7.8 Colima earthquake in Mexico, which occurred on January 23, 2003 the surface air temperature map over Mexico at 14:00 LT on January 14, 2003 showed that local maximum temperature was close to the epicenter of the impending earthquake (Pulinets et al., 2006a, b). Wu et al. (2012) and Qin et al. (2012a) used surface latent heat flux (SLHF), outgoing longwave radiation (OLR), and atmospheric temperature data, to study two earthquakes in China (M7.3 Yutian and M8.0 Wenchuan, both in 2008), and the 2010 M7.1 Christchurch earthquake in New Zealand, finding composite thermal anomalies before all these earthquakes. Moreover, Qin et al. (2012b) analyzed air temperature and infrared radiometer (IR) satellite data to find a thermal anomaly before the 2012 Emilia (north Italy) major earthquakes (M5.9 and M5.8). Here we study the changes in air temperature data, NCEP-FNL data, and AMSR-E microwave brightness temperature data before the Baja California M7.2 earthquake, in order to find some prior anomalies.

\section{Data analysis}

First we plotted the weather station surface air temperature data from January 1 to April 10, 2010 (top of Fig. 2). The data are derived from the Mexicali surface station, whose location is $32.667^{\circ} \mathrm{N}, 115.458^{\circ}$ $\mathrm{W}$, around $50 \mathrm{~km}$ north from the epicenter. It is the nearest station to this point. Data were downloaded from the National Climatic Data Center (NCDC) of the National Oceanic and Atmospheric Administration (NOAA). The data show that there is a peak value $\left(24.5^{\circ} \mathrm{C}\right)$ on March 30 , which is also the largest value in the prior 90 days. Checking other stations north of Mexicali, we did not find similar peaks. For example, the Marine Corps Air Station (MCAS) at Yuma $\left(32.65^{\circ} \mathrm{N}, 114.6^{\circ} \mathrm{W}\right)$, which is about $78 \mathrm{~km}$ away from the epicenter, shows no peaks on March 30. Its temperature increases only $1.2^{\circ} \mathrm{C}$ compared to that of March 29, while the Mexicali temperature increases $5.2^{\circ} \mathrm{C}$ (bottom of Fig. 2). Due to the absence of weather data for Mexico, we could not plot the spatial distribution of temperature change in the epicenter area, so we turned to the National Centers for Environmental Prediction Final Operational Global Analysis (NCEP-FNL) reanalysis data, which provide temperature data with $1^{\circ}$ spatial resolution and 6 hours temporal resolution.

NCEP-FNL provides global air temperature, humidity, pressure, sea surface temperature and so on every six hours with $1^{\circ}$ resolution. It uses a state-ofthe-art analysis method to perform data assimilation with ground weather station and satellite data. These data have no such problems as clouds cover or interpolation, and they are continuously providing a reliable database to analyze thermal anomalies eventually present before the earthquakes. Figure 3 shows the air temperature difference between 00:00 UTC on March 31 and 00:00 UTC on March 30 (18:00 LT) at the $1000 \mathrm{hPa}$ level. We can see clearly that the greater difference in temperature (around $7{ }^{\circ} \mathrm{C}$ ) is exactly in the epicenter area; it is also the maximum value in the whole North American subcontinent, while in other areas there is only a medium-low temperature differ- 


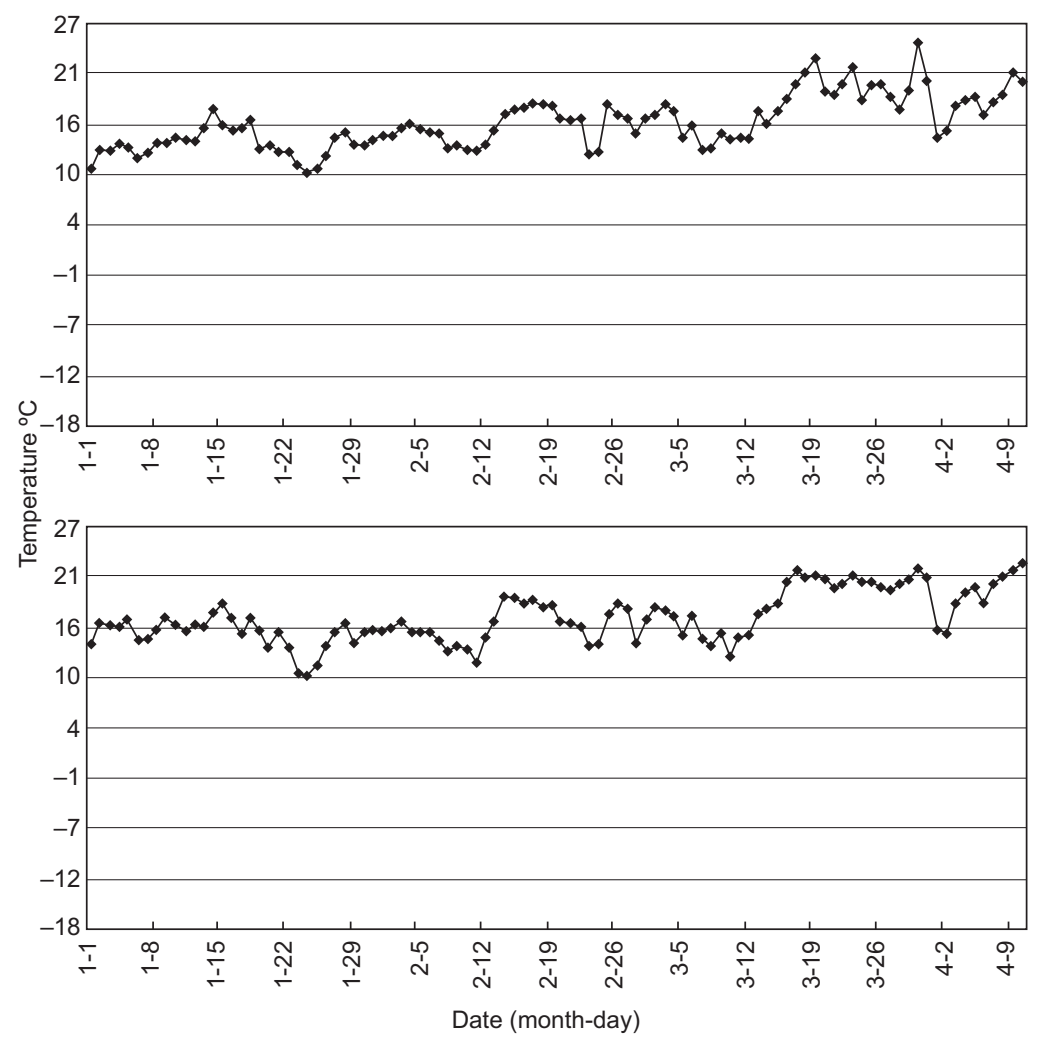

Fig. 2. Surface air temperature data of Mexicali (top) and the MCAS Yuma (bottom) weather station from January 1 to April 10, 2010.

ence. The map area is located between $40-160^{\circ} \mathrm{W}$ and $0-60^{\circ} \mathrm{N}$, with a spatial resolution of $1^{\circ}$, which means there is a total of $120 \times 60=7200$ grid points in this area. Temperature shows its maximum difference only in the epicenter grid point, so the probability of this occurring by simple chance is $1 / 7200$. The west coast of the American continent from Alaska to Mexico $\left(60-0^{\circ} \mathrm{N}\right)$ and the Haitiarea are earthquake-prone. In-

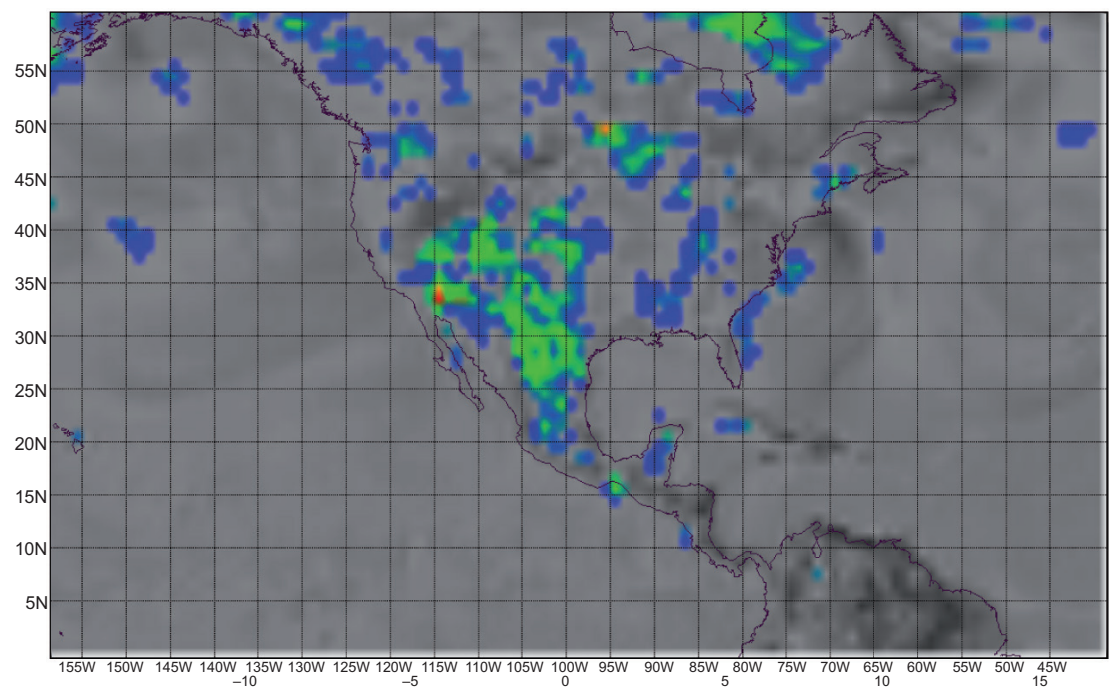

Fig. 3. NCEP-FNL air temperature difference (at $1000 \mathrm{hPa}$ ) map on March 31, 2010. 
cluding both areas, there are about 100 grids in which earthquakes bigger than M7.0 can take place. In the large area shown in Figure 3, the probability for a grid to have the highest temperature change concurring with a M7.0 earthquake is $1 / 7200 \times 1 / 100=1 / 720$ 000. Suppose that any day from March 20 to April 10 can have the highest temperature, so the odds are $1 / 20$. If we consider that the three events coincided in the same grid, the likelihood will be $1 / 720000 \times 1 / 20$ $=1 / 1440000$. This very small probability shows the thermal anomaly is very likely related to the earthquake. Admittedly, in Figure 3 there is also another high temperature spot northeast to the epicenter, located at $95^{\circ} \mathrm{W}, 50^{\circ} \mathrm{N}$. It is the second warmest spot in the whole area, which is located in high latitude where no earthquake activities bigger than M3.0 have taken place in the last 40 years. So it is a very stable area and the recorded temperatures could not have its origin in a seismic thermal anomaly. The possible cause need to be further investigated.

We also examined the microwave brightness temperature data derived from the Advanced Microwave Scanning Radiometer onboard the Earth Observing System satellite (AMSR-E). AMSR-E is a six-frequency dual-polarized total-power passive microwave radiometer that measures water-related geophysical parameters supporting global change science and monitoring efforts. Here we used the AMSR-E L2A global swath spatially resampled brightness temperatures product in $89.0 \mathrm{GHz}$ frequency. This data are resampled to obtain spatial consistency, and therefore are available at a variety of resolutions that correspond to the footprint sizes of the observations such as $56,38,24,21,12$, and $5.4 \mathrm{~km}$. The corresponding resolution for $89.0 \mathrm{GHz}$ is $5.4 \mathrm{~km}$ (Ashcroft and Wentz, 2006). The results show that the microwave brightness temperature reaches its peak on March 31, in quasi-synchronism with the air temperature anomaly in Figures 3 and 4. Then it decreases until April 4, when the earthquake occurred (Fig. 4).

\section{Discussion and conclusion}

As a mechanism for the anomalous temperature increase, Pulinets et al. (2006) suggest that in seismically active areas the increased radon emanation from active faults is the primary source of air ionization. Water molecules attach to the newly formed ions and this leads to an air temperature change. Freund
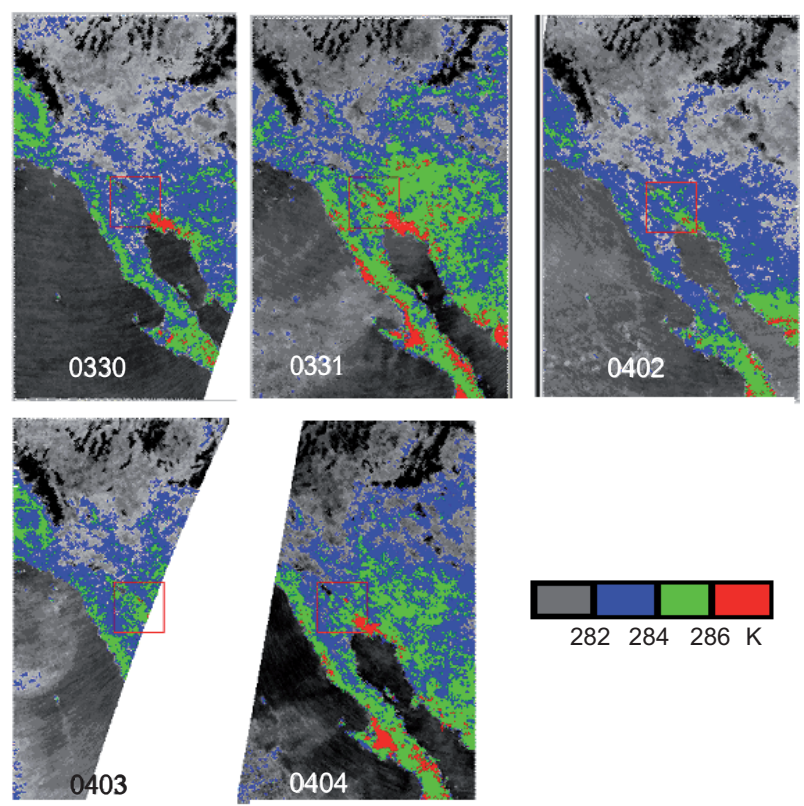

Fig. 4. AMSR-E microwave brightness temperature map from March 30 to April 4, 2010.

(2007a, b) performed some rock experiments and found that when rocks are subjected to stress, dormant electronic charge carriers are activated. The charge carriers are electrons and defect electrons, also known as positive holes or p-holes. P-holes will produce a positive surface charge over a wide area around the future epicenter, and then lead to a local thermal infrared emission. These two explanations seem different, but both of them are related with an electric coupling between solid earth, atmosphere, and ionosphere.

For recognizing earthquake anomalies with multiple observation parameters from EOS, Wu et al. (2012) defined three criterions: deviation (D), time synchronism (T), and space consistency (S), and applied them to thermal anomaly analysis. They called the new method DTS-T, which has been successfully applied in China, New Zeeland and Italy (Wu et al., 2012; Qin et al., 2011; Qin et al., 2012a, b). In this paper, referring to the DTS-T method, we have analyzed multiple thermal parameters to detect earthquake anomalies before the Baja California M7.2 earthquake. The air temperature data from the Mexicali weather station shows a maximum value five days before the event, while stations around $100 \mathrm{~km}$ away do not show any clear temperature anomaly. This means that the seismic thermal anomaly is confined to a restricted 
area near or enclosing the future epicenter. NCEPFNL data shows a maximum temperature difference of $7^{\circ} \mathrm{C}$ in the epicenter grid. Compared with the $4-5{ }^{\circ} \mathrm{C}$ temperature difference background, the increase caused by the earthquakes is around $2-3{ }^{\circ} \mathrm{C}$, which is similar to the value reported by Tronin (1996) and Saraf and Choudhury (2004). The NCEP data anomaly also corresponds well to the epicenter location, and this could provide a method to estimate the future epicenter. AMSR-E microwave brightness temperature data also show a thermal anomaly before the earthquake. The results of multiple thermal parameters analysis obey well the DTS criterions, which hence can be considered as convincing seismic thermal anomalies. The above analysis shows that the current weather station density is not sufficient to adequately determine the seismic anomaly. The distance between stations should be lesser than $50 \mathrm{~km}$ in order to identify the anomaly and estimate the epicenter with a reasonable margin of error.

\section{Acknowledgements}

This work was supported by the National Science Foundation of China (41071280). Air temperature data was provided by the National Climatic Data Center of NOAA; NCEP-FNL data was provided by NOAA/OAR/ESRL PSD, Boulder, Colorado; and AMSR-E data was provided by the National Snow and Ice Data Center. We greatly appreciate their help. We greatly acknowledge the reviewers' help for improving this paper's quality.

\section{References}

Akhoondzadeh M. and M. R. Saradjian, 2011. TEC variations analysis concerning Haiti (January 12, 2010) and Samoa (September 29, 2009) earthquakes. $A d v$. Space Res. 47, 94-104.

Ashcroft P. and F. Wentz, 2006. AMSR-E/Aqua L2A global swath spatially-resampled brightness temperatures V002. National Snow and Ice Data Center, Boulder, Colorado. Available at: http://nsidc.org/data/ae_12a.html.

Dunajecka M. A. and S. A. Pulinets, 2005. Atmospheric and thermal anomalies observed around the time of strong earthquakes in Mexico. Atmósfera 18, 235-247.
Freund F. T., 2007a. Pre-earthquake signals - Part I: Deviatory stresses turn rocks into a source of electric currents. Nat. Hazard. Earth Sys. 7, 535-541, doi:10.5194/ nhess-7-535-2007.

Freund F. T., 2007b. Pre-earthquake signals - Part II: Flow of battery currents in the crust. Nat. Hazard. Earth Sys. 7, 543-548, doi:10.5194/nhess-7-543-2007.

Pulinets S., D. Ouzounov, A. Karelin, K. Boyarchuk and L. Pokhmelnykh, 2006a. The physical nature of thermal anomalies observed before strong earthquakes. Phys. Chem. Earth 31, 143-153.

Pulinets S. A., D. Ouzounov, L. Ciraolo, R. Singh, G. Cervone, A. Leyva, M. Dunajecka, A. V. Karelin, K. A. Boyarchuk and A. Kotsarenko, 2006b. Thermal, atmospheric and ionospheric anomalies around the time of Colima M7.8 earthquake of January 21, 2003. Ann. Geophys. 24, 835-849.

Pulinets S. A. and K. G. Tsybulyaa, 2010. Unique variations of the total electron content in the preparation period of Haitian earthquake (M7.0) on January 12, 2010. Geomagn. Aeronomy 50, 686-689.

Qin K., L. X. Wu, A. De Santis and H. Wang, 2011. Surface latent heat flux anomalies before the MS 7.1 New Zealand earthquake 2010. Chin. Sci. Bull. 56, 3273-3280.

Qin K., L. X. Wu, A. De Santis, J. Meng, W. Y. Ma and G. Cianchini, 2012a. Quasi-synchronous multiple-parameter anomalies associated with the 2010-2011 New Zealand earthquake sequence. Nat. Hazards Earth Sys. 12, 1059-1072.

Qin K., L. X. Wu, A. De Santis and G. Cianchini, 2012b. Preliminary analysis of surface temperature anomalies preceding the two major 2012 Emilia (Italy) earthquakes. Ann. Geophys. 55, 823-828.

Saraf A. K. and S. Choudhury, 2004. Satellite detects surface thermal anomalies associated with the Algerian earthquakes of May 2003. Int. J. Remote Sens. 26, 2705-2713.

Tronin A. A., 1996. Satellite thermal survey - a new tool for the studies of seismoactive regions. Int. J. Remote Sens. 17, 1439-1455.

Wu L. X., K. Qin and S. J. Liu, 2012. GEOSS-based thermal parameters analysis for earthquake anomaly recognition. Proceedings of IEEE 100, 2891-2907. 